\title{
Characterization of four clones derived from human adenocarcinoma cell line, HT29, and analysis of their response to sodium butyrate
}

\author{
JITKA STOKROVÁ, EVA SLONCOVÁ, VLASTA SOVOVÁ, DANA KUCEROVÁ, VOJTECH ZÍLA, \\ JOLANA TURECKOVÁ, MARTINA VOJTECHOVÁ, JAN KORB and ZDENA TUHÁCKOVÁ
}

Institute of Molecular Genetics, Academy of Sciences of the Czech Republic, Flemingovo nám. 2, 16637 Prague 6, Czech Republic

Received September 13, 2005; Accepted November 4, 2005

\begin{abstract}
The differentiation of colorectal cancer cells is associated with the arrest of tumor growth and tumor regression. However, the mechanism of such tumor cell differentiation has not yet been elucidated. Several adenocarcinoma cell lines, including HT29 which differentiates only upon stimulation with a differentiation agent, have been used for the study of colorectal cells. Since we had previously obtained variable results during analyses of these cells, we selected several clones of this cell line. In this study, four clones of the parental HT29 cells, H8, G9, G10 and A3, were characterized. All of them differentiated upon treatment with sodium butyrate as the differentiation agent but they appeared different in their response regarding some of the markers of differentiation. As revealed by ultrastructural analysis, $\mathrm{H} 8$ and G10 clones formed numerous intercellular cysts with microvilli whereas these structures were found only ocassionally in G9 and A3 clones. An elevated level of the indicator of cell differentiation, CEACAM 1, was found in H8 and G10 clones and the activity of alkaline phosphatase, another important marker of colorectal cell differentiation, was up-regulated and highly increased upon butyrate treatment in the $\mathrm{H} 8$ clone. Phosphorylation of p38 MAPK was increased in $\mathrm{H} 8$ and A 3 butyrate-treated clones. According to the levels of cleaved PARP and activated caspase-3, the apoptotic response to butyrate appeared similar in all four clones, while electronoptic analysis revealed that clones G9 and A3 were more perceptive to butyrate-induced
\end{abstract}

Correspondence to: Dr Zdena Tuhácková, Institute of Molecular Genetics, Academy of Sciences of the Czech Republic, Flemingovo nám. 2, 16637 Praha 6, Czech Republic

E-mail: tuhack@img.cas.cz

Abbreviatons: PARP, poly(ADP-ribose) polymerase; CEACAM1, carcinoembryonic antigen-related cell adhesion molecule 1; p38 MAPK, p38 MAP kinase

Key words: adenocarcinoma, HT29 cell line, cell clones, differentiation, sodium butyrate, apoptosis, ultrastructure apoptosis. In conclusion, our data showed considerable heterogeneity in morphology and some enzymatic activity of the cloned cells. This fact may contribute to the evidence that many HT29 cells possess multipotent information similar to that of stem cells of the normal intestinal crypt.

\section{Introduction}

The cell lines isolated and cultured from human colonic adenocarcinoma have been considered as a useful tool for studying many questions of cell biology, particularly cell differentiation in vitro. There are many cell lines derived from human colorectal carcinomas, some of which represent a model for inducing transient differentiation. In this respect, the HT29 cell line is an excellent subject for such studies, since HT29 cells can differentiate only upon treatment with a differentiation agent and the differentiation process in these cells seems to be similar to that observed during the embryonic development of intestine (1).

In the HT29 cell line, differentiation and a certain degree of polarization can be induced by various agents, such as sodium butyrate (2-4), or glucose deprivation (5). However, the mode and degree of the response of HT29 cells to differentiation and apoptosis-inducing agents appeared to be relatively heterogenous. Sodium butyrate has significant physiological relevance to the integrity and function of the colonic epithelium and may be an important factor in the pathogenesis of diseases of the colonic epithelium, such as colorectal cancer and colitis (6). In cancer cell lines, butyrate exerts several antitumor effects, including inhibition of cell proliferation, stimulation of cell differentiation and induction of apoptosis (7).

The finding that a large part of HT29 cells, which are mostly undifferentiated in standard cell culture, differentiate when glucose is replaced by galactose in the medium (5), initiated the isolation of HT29 cell clones in several laboratories. Some clones differentiated into the absorptive cell type (8-10), others showed mucus-secreting character $(11,12)$.

In previous experiments, we have observed a heterogeneity of colorectal cancer cells HT29 in response to sodium butyrate treatment and/or glucose deprivation, two different agents that can induce transient differentiation and apoptosis in these cells (13). A population of only one type of these cells 
therefore appeared to be necessary for a detailed study of transiently induced differentiation in colorectal carcinoma cells HT29. For this purpose, we have cloned parental HT29 cells to receive cell clones that may provide a better model for the molecular and morphological study of these cancer cells.

In the present study, we selected four clones of HT29 cells (H8, G9, G10, A3) and examined some of their biochemical and morphological characteristics and responses to butyrateinduced differentiation. The relationship between biochemical markers of differentiation and ultrastructural characteristics are discussed.

\section{Materials and methods}

Biotinylated anti-mouse polyclonal IgG and the Vectastain ABC kit were obtained from Vector Laboratories, Burlingame, USA. Monoclonal antibody anti-CEACAM1, TEC-11 (14), was from Dr Dráber. Polyclonal anti-PARP, anti-cleaved PARP, anti-p38, anti-phospho-p38(Thr180/Tyr182) antibodies were from New England BioLabs. Peroxidaseconjugated secondary anti-rabbit and anti-mouse antibodies were from Bio-Rad and ECL Western blotting detection kits were from Amersham. Epoxy resin AGAR 100 was from Gröpl, Tuln, Austria.

Cell culture and clone isolation. Colorectal cell line HT29 (ATCC, Rockville, MD) and its clones were cultured in Eagle's minimum essential medium supplemented with $10 \%$ foetal calf serum (FCS) in the absence or presence of $5 \mathrm{mM}$ sodium butyrate for 5 days. The clones were prepared by end-point dilution of the parental cells, HT29, seeded in 96-well plates. Only wells containing one colony growing from a single cell were maintained, the cells were multiplied and their characteristic features were analysed. From approximately 15 preliminary characterized clones, the clones $C 9, H 8, A 3$, and $G 10$ were subjected to further analysis.

Immunocytochemical analysis. Cells grown on slides either untreated or treated with $5 \mathrm{mM}$ sodium butyrate for 5 days were fixed in solution containing $4 \%$ paraformaldehyde and $0.2 \%$ Triton X-100 in PBS for $10 \mathrm{~min}$ at room temperature. After washing with PBS, the slides were overlayed with $0.2 \%$ Triton X-100 in PBS for 15 min, washed in PBS and treated with $0.1 \%$ sodium azide containing $3 \%$ hydrogen peroxide to inhibit endogenous peroxidase. The cells were incubated overnight with the appropriate primary antibody at $4^{\circ} \mathrm{C}$, washed with Tris-buffered saline $\mathrm{pH} 7.6$ (TBS) and incubated with biotinylated secondary antibody for $30 \mathrm{~min}$. The Vectastain $\mathrm{ABC}$ kit was used to reveal antibody-antigen complexes by the streptavidin-biotin technique and horseradish peroxidase (HRP) with diaminobenzidine (DAB) was used as an enzymesubstrate system. Finally, slides were counterstained with Harris' haematoxylin.

Alkaline phosphatase assay. The cells were lysed by sonication in lysis buffer $\mathrm{A}[10 \%$ diethanolamine, $0.5 \mathrm{mM} \mathrm{MgCl}$ ( $\mathrm{pH}$ 9.8)]. The lysates cleared by centrifugation at $15000 \mathrm{x}$ g for 3 min were mixed with the substrate for alkaline phosphatase, 4-nitrophenylphosphate disodium (NPP) dissolved in lysis buffer A $(2.8 \mathrm{mg} / \mathrm{ml})$, and the mixtures were incubated for $30 \mathrm{~min}$ at $37^{\circ} \mathrm{C}$. The reaction was stopped with $3 \mathrm{M} \mathrm{NaOH}$. Absorbance at $405 \mathrm{~nm}$ was measured with an ELISA reader and the enzyme activity was calculated using the molar extinction coefficient $\left(\varepsilon_{405}=20.2 \mu \mathrm{mol}^{-1}\right)$ obtained from a $\mathrm{p}$ nitrophenol calibration curve.

Cell lysis. Cells were lysed in ice-cold extraction buffer B (25 mM HEPES, 1\% Triton X-100, 2 mM EDTA, $0.1 \mathrm{M} \mathrm{NaCl}$, $25 \mathrm{mM} \mathrm{NaF}, 1 \mathrm{mM}$ sodium orthovanadate, $0.5 \mathrm{mM}$ PMSF, aprotinin $1 \mu \mathrm{g} / \mathrm{ml}$ ) for $60 \mathrm{~min}$, unless otherwise indicated. The cell extracts were clarified by centrifugation at $12000 \mathrm{x} \mathrm{g}$ for $10 \mathrm{~min}$ at $4^{\circ} \mathrm{C}$ and supernatants were assayed for protein concentration. For PARP [poly(ADP-ribose) polymerase] and caspase- 3 analyses, the cells were extracted by adding a boiling lysis solution (five volumes of the cell pellet) containing $1 \%$ SDS, $10 \mathrm{mM}$ Tris-pH 7.4, $1.0 \mathrm{mM}$ sodium vanadate and boiled for $5 \mathrm{~min}$. The viscosity was reduced by several passages through a 22-gauge needle.

Immunoblot analysis. Total proteins (30-60 $\mu \mathrm{g})$ were subjected to SDS-PAGE and electrophoretically transferred to nylon membranes (Immobilon-P, Millipore). Non-specific binding was blocked with 5\% (w/v) milk in PBS-T (phosphate-buffered saline $\mathrm{pH} 7.5,0.1 \%$ Tween-20) and the membranes were analysed with a specific primary antibody. After washing, the membranes were incubated with the appropriate secondary antibody. Detection of the analysed proteins was performed by enhanced chemiluminescence (ECL, Amersham).

Ultrastructural analysis. The cells of HT29 clones, untreated or treated with $5 \mathrm{mM}$ sodium butyrate for 5 days were analysed. After fixation in situ for $1 \mathrm{~h}$ at $4^{\circ} \mathrm{C}$ with $3 \%$ glutaraldehyde

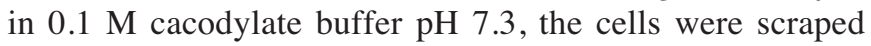
off and postfixed for $1 \mathrm{~h}$ at $4{ }^{\circ} \mathrm{C}$ in $1 \% \mathrm{OsO}_{4}$. Fixed cells were dehydrated in graded ethanol solutions and embedded in epoxy resin AGAR 100 (Gröpl) as described (15). Ultrastructural analysis was performed on ultrathin sections stained with uranyl acetate and lead citrate. The samples were examined in a JEOL JEM 1200Ex electron microscope.

\section{Results}

Four different cell clones, $G 9, H 8, A 3$, and $G 10$, were selected from approximately 15 HT29 cell clones for a detailed study of colorectal cancer cells and their transient differentiation induced by sodium butyrate. In the present study, the cells of these clones, untreated or treated with $5 \mathrm{mM}$ sodium butyrate, were characterized morphologically and biochemically.

Substructural characteristics of HT29 cell clones G9, H8, $A 3$, and G10. Ultrastructural analysis revealed morphological differences among individual HT29 cell clones and a heterogeneous pattern of the cells in each clone was observed. Despite this finding, it was possible to divide the clones into two phenotypes: i) $H 8$ and $G 9$ clones, and ii) $G 10$ and $A 3$ clones, of the HT29 cell line.

A high percentage of the cells of both $H 8$ and $G 9$ clones displayed an undifferentiated character, similar to the parental HT29 cell line. The cells were connected only by desmosomes 

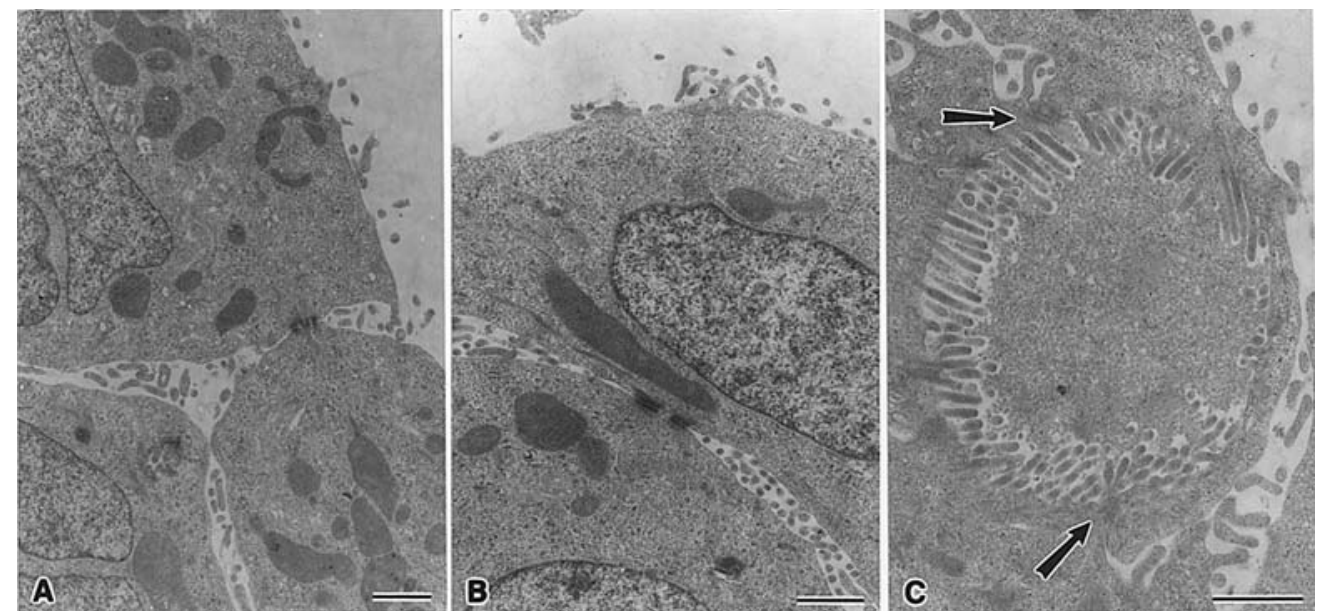

Figure 1. Ultrastructure of the non-treated cells of $H 8$ and $G 9$ clones. Undifferentiated features of $H 8$ and $G 9$ cells (A and B). Intercellular cyst in some cells of the $H 8$ clone (C). Tight junctional complexes are indicated by arrows. Bars $=1 \mu \mathrm{m}$.
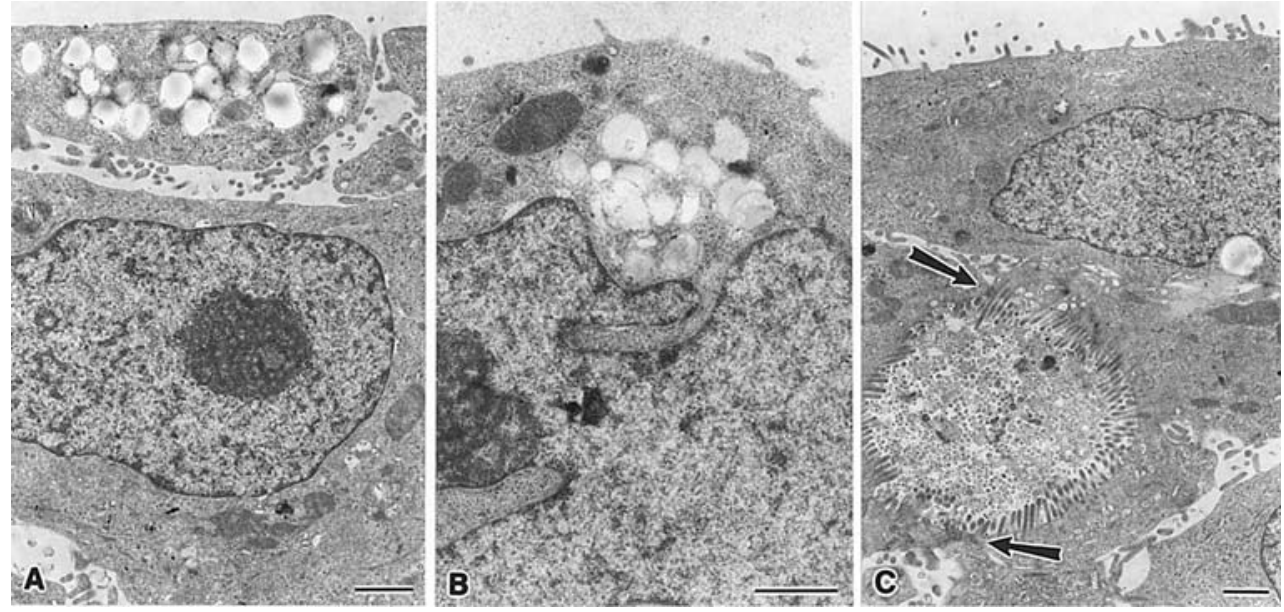

Figure 2. Ultrastructure of the non-treated cells of $G 10$ and $A 3$ clones. Goblet-like cells of $G 10$ and $A 3$ clones (A and B). Intercellular cyst in some cells of the G10 clone (C). Tight junctional complexes are indicated by arrows. Bars $=1 \mu \mathrm{m}$.

and devoid of junctional complexes (Fig. 1A and B). Nevertheless, approximately $30 \%$ of the cells of the $H 8$ clone were partially differentiated; indicated by formation of intercellular cysts, similar to lumina, with a diameter of $4 \mu \mathrm{m}$ on average, with well-formed microvilli on their surface (Fig. 1C). The connections, similar to tight junction, were observed among the cells surrounding the intercellular cysts. These cysts were filled either with electron dense material or with small vesicles. Such cysts were only rarely found in the cells of the G9 clone (data not shown). Neither markers of apoptosis nor presence of secreting granules were observed in the analysed $H 8$ and $G 9$ cell clones.

In $G 10$ and $A 3$ clones, a high proportion of the cells also revealed undifferentiated features. However, in contrast to $H 8$ and $G 9$ clones, approximately $15 \%$ of $G 10$ cells and $7 \%$ of $A 3$ cells displayed a goblet-like structure with secreting granula (Fig. 2A and B). The intercellular cysts with oriented microvilli, approximately $6 \mu \mathrm{m}$ in diameter, were observed in $30 \%$ of the G10 clone cells (Fig. 2C), while they were found only occasionally in the $A 3$ clone (data not shown). Clumped chromatin in some of the cells of both these clones suggested early stages of the apoptotic process.
Effect of sodium butyrate on morphological characteristics of HT29 cell clones. All four HT29 cell clones responded morphologically to sodium butyrate, but to a different extent.

$H 8$ and $G 9$ cell clones. Upon butyrate treatment, the cells of the $H 8$ clone revealed only a low percentage of oriented cells with a brush border on their apical surface, while the number of intercellular cysts increased considerably. They were observed in almost $80 \%$ of cells. Surrounding cells possessed an oriented brush border with dense microvilli on their surface (Fig. 3A) and were connected by structures similar to tight junction. The cysts of $5.5 \mu \mathrm{m}$ in diameter found in this cell clone were filled with electron dense and granular material. Also, many small vesicles were present inside these cysts. In contrast, butyrate treatment did not increase the cyst numbers in the cells of the $G 9$ clone. However, a part of these cells revealed polarized columnar absorptive cells with a brush border on their apical surface (Fig. 3B). In the proximity of the apical surface of oriented cells, some secreting granules were observed. Rarely found intracellular cysts, with a diameter of approximately $10 \mu \mathrm{m}$, were devoid of any material (data not shown). The presence of giant mitochondria in some cells suggested the first stages of apoptosis (Fig. 3C). 

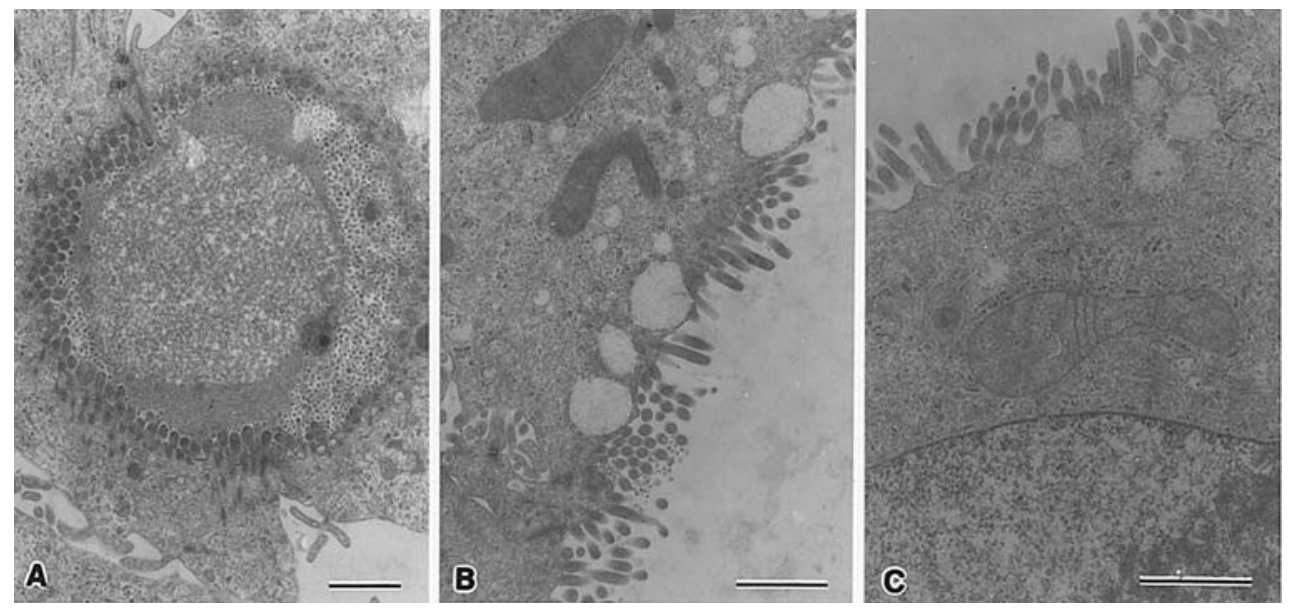

Figure 3. Ultrastructural changes of $H 8$ and $G 9$ cloned cells after NaBT treatment. Intercellular cyst in the cells of the $H 8$ clone (A). Columnar absorptive cells (B) and giant mitochondrion (C) in the cells of the $G 9$ clone. Bars $=1 \mu \mathrm{m}$.
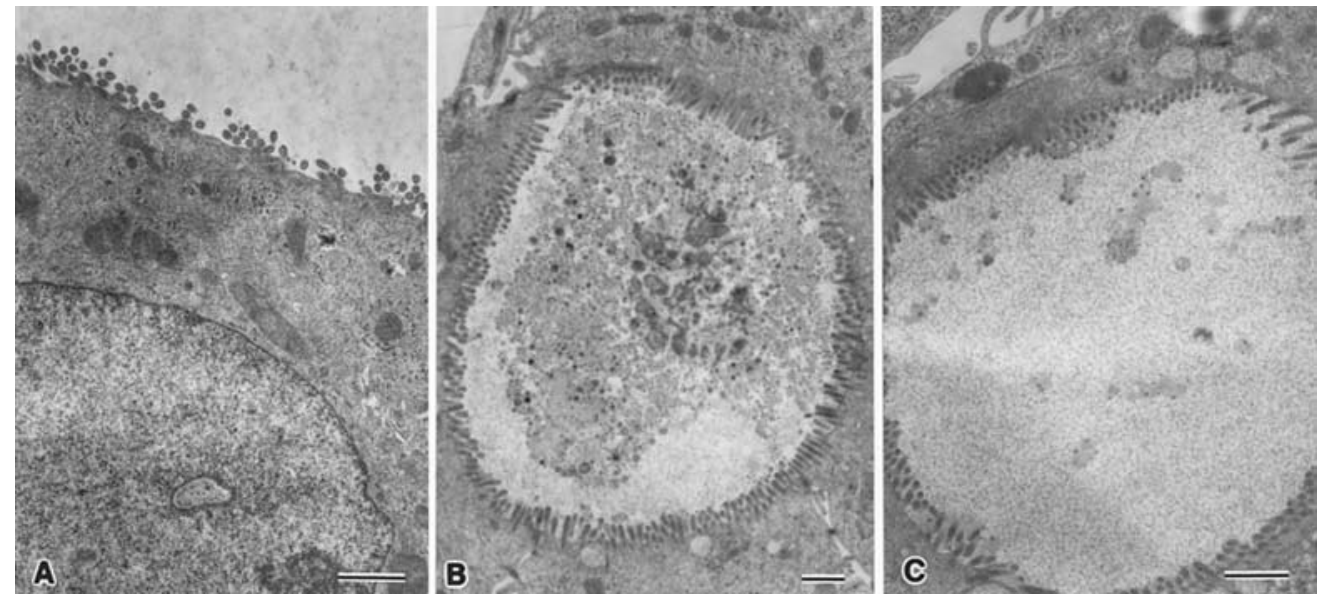

Figure 4. Ultrastructural changes of $G 10$ and $A 3$ cloned cells after NaBT treatment. Columnar absorptive cells (A) and cyst (B) in the cells of the $G 10$ clone. Cyst present in the cells of $A 3$ cloned cells $(C)$. Bars $=1 \mu \mathrm{m}$.

G10 and A3 cell clones. Approximately $30 \%$ of $G 10$ clone cells revealed the brush border on their apical surface after sodium butyrate treatment (Fig. 4A). The number of goblet-like cells with secreting granules increased markedly. Huge intracellular cysts, approximately $10 \mu \mathrm{m}$ in diameter, were found. The number of these cysts apparently increased in comparison with the non-treated cells. The dense microvilli were oriented on the surface of these structures. The electrondense granular and vesicular materials were localized inside them (Fig. 4B). Moreover, some cysts of $12 \mu \mathrm{m}$ in diameter that were almost without microvilli were found in the cells of the $G 10$ clone as well.

On the other hand, butyrate-treated cells of the $A 3$ clone were more heterogeneous. Only a small part of these cells possessed the brush border, but with non-properly organized microvilli on their surface. The treatment of the cells with butyrate induced an increasing number of goblet-like cells, but only slightly in the $A 3$ clone. The amount of intercellular cysts also increased in the $A 3$ cells upon butyrate treatment, but was lower compared to the $G 10$ clone. The cysts of $7 \mu \mathrm{m}$ in diameter were devoid of electron dense and vesicular material
(Fig. 4C). Later stages of apoptosis were observed in some cells of this $A 3$ clone.

Analysis of some differentiation markers in HT29 cell clones G9, H8, A3, and G10. CEACAM1 (carcinoembryonic antigenrelated cell adhesion molecule 1) is considered to be one of the indicators of differentiation with a tumor-suppressive function whose expression is down-regulated in many tumors (16). We examined the presence of CEACAM1 in HT29 cell clones by immunoblotting (Fig. 5) and by immunohistochemical analysis, which revealed that CEACAM1 was localized mainly in the cell membrane and intracellular cysts (data not shown). As seen in Fig. 5, the expression of CEACAM1 appeared elevated in more differentiated cell clones, $H 8$ and $G 10$, which more resemble normal enterocytes, than in the less differentiated clones, $G 9$ and $A 3$, according to their substructural characterization (Figs. 1A and B; and 2A and B). Upon butyrate treatment, the expression of CEACAM1 increased in all analysed clones (data not shown).

On the other hand, the activity of alkaline phosphatase (AP) was changed differently upon butyrate treatment in 


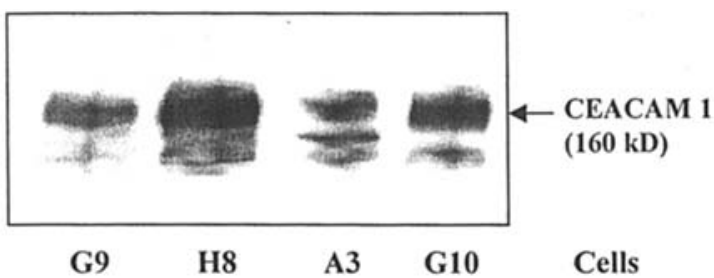

Figure 5. Amounts of CEACAM1 in HT29 clones G9, H8, A3, and G10. Western blot from the SDS-PA gels of the extracts $(40 \mu \mathrm{g})$ of the analysed cells using anti-CEACAM1 antibody.

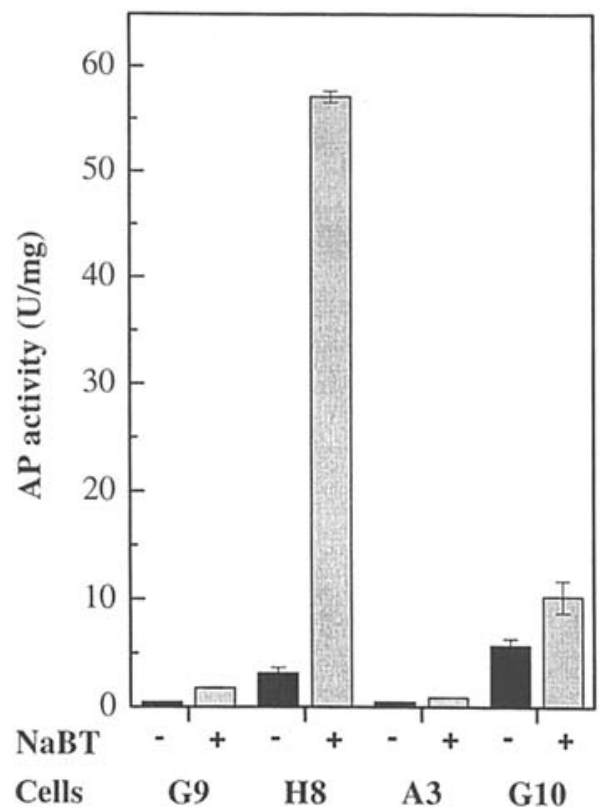

Figure 6. Examination of the effect of butyrate on alkaline phosphatase (AP) activity in HT29 clones $G 9, H 8, A 3$, and G10. The cells were either nontreated (-) or treated (+) with $5 \mathrm{mM}$ sodium butyrate for 5 days. The activity of AP was analysed as described in Materials and methods. Each point is an average of duplicate values of two separate experiments.

the individual cell clones (Fig. 6). The presence of a highly activated AP in the untreated $H 8$ clone seems to be in agreement with the observation that approximately $30 \%$ of cells of the $H 8$ clone were partially differentiated (Fig. 1C). Upon butyrate treatment, the hyperstimulation of AP activity ( $>20$-fold increase) was induced in $H 8$ cells while, in all other clones $(G 9, A 3, G 10)$, the increase in the enzymatic activity of AP was much lower (0.5- to 2-fold).

p38 MAP kinase, which is another protein considered as one of the indicators of differentiation in certain cell types $(17,18)$, was found phosphorylated and thus activated only in $H 8$ cells. Upon treatment with butyrate, the increased phosphorylation of Thr180/Tyr182 residues in the molecule of p38 MAPK was found in the $H 8$ clone and also in the cells of the $A 3$ clone (Fig. 7).

An apoptotic response to butyrate in $H 8, G 9, A 3$, and $G 10$ cell clones was examined by analysis of some biochemical markers of apoptosis, such as cleavage of PARP (Fig. 8A) and caspase-3 activation (Fig. 8B). In each of the isolated clones, the apoptotic response to butyrate treatment was approximately of the same extent. This is indicated by the

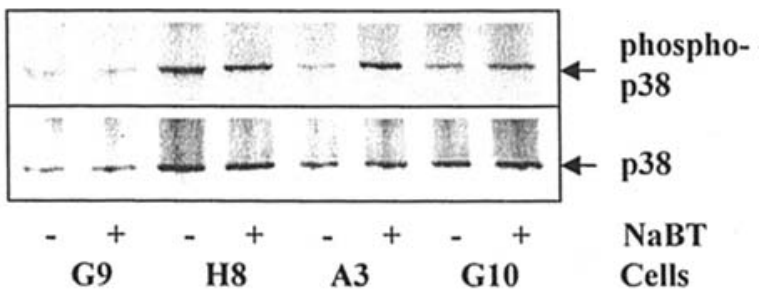

Figure 7. Analysis of p38 MAPK phosphorylation in HT29 clones $G 9, H 8$, $A 3$, and G10. The cells were either non-treated (-) or treated (+) with $5 \mathrm{mM}$ sodium butyrate for 5 days. Crude cell extracts were analysed by SDS-PAGE followed by Western blotting using anti-phospho-p38(Thr180/Tyr182) and anti-p38 antibodies as indicated.

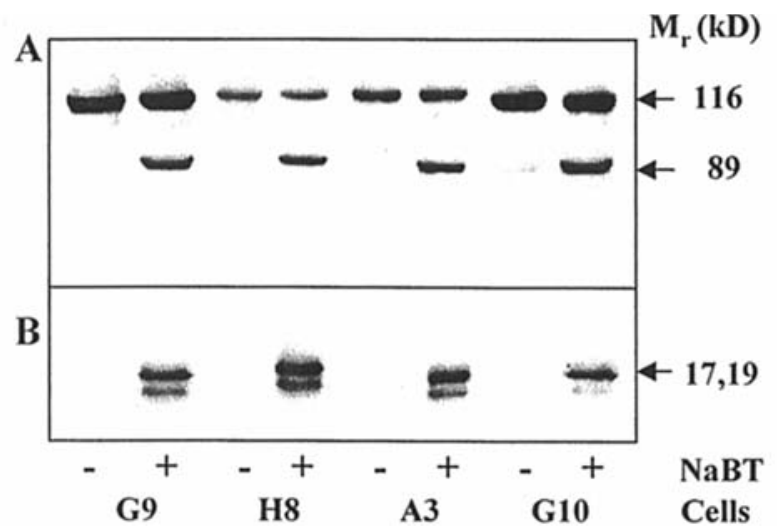

Figure 8. Examination of the apoptotic response to butyrate treatment in HT29 clones $G 9, H 8, A 3$, and G10. The cells were either non-treated (-) or treated (+) with $5 \mathrm{mM}$ sodium butyrate for 2 days and lysed as described in Materials and methods; both floating and adherent cells were collected for protein extraction. Crude cell extracts were analysed by SDS-PAGE followed by Western blotting using anti-PARP and anti-cleaved PARP antibody (A), and anti-cleaved caspase- 3 antibody (B). The positions of the intact PARP $\left(M_{r}=116 \mathrm{kD}\right)$ fragment of cleaved PARP $\left(M_{r}=89 k D\right)(A)$, and of activated caspase-3 $\left(\mathrm{M}_{\mathrm{r}}=17.19 \mathrm{kD}\right)(\mathrm{B})$ are indicated.

presence of PARP fragment $\left(\mathrm{M}_{\mathrm{r}}=89\right)$ and cleaved caspase-3 $\left(M_{r}=17.9\right)$ in the cells of all clones treated with sodium butyrate.

\section{Discussion}

In the present study, the cloning of parental HT29 cells was performed with the expectation to obtain a population of one type of the cells that may provide a better model for molecular and morphological studies of these cancer cells. Nevertheless, morphological, immunocytological and biochemical analyses of the isolated cell clones showed some differences, particularly in their morphology and in the activity and expression of several differentiation markers, such as the presence of CEACAM1, alkaline phosphatase activity, and phosphorylation of p38 MAPK. The observation that the density of the HT29 cell culture can influence the final effects of differentiation induced by glucose deprivation (19), led us to examine HT29 cells untreated or treated with sodium butyrate at different confluencies. We have found that only confluent culture of HT29 cells provided the most reproducible results (data not shown) and, thus, we only used confluent culture of HT29 cells for the analyses in this study. 
Substructural analyses of four clones of the HT29 cell line showed that the parental population of HT29 cells is heterogenous in several features. This cell line consists of cells that have a potential to differentiate into distinct cell types as do cells of the normal intestinal epithelium. The cells from which H8 and G9 clones were established were changed by induced differentiation into an absorptive type of cells, while G10 and A3 clones resembled goblet-like cells after butyrate treatment. However, cells converging to the same differentiation lineage can start from various levels of differentiation, since untreated cells of H8 and G10 clones already contain approximately $30 \%$ partially differentiated cells.

The ultrastructural finding that approximately $30 \%$ of cells of the $\mathrm{H} 8$ clone were partially differentiated, according to the presence of the intercellular vacuoles, may explain a high basic activity of alkaline phosphatase found in these cells compared to the cells of other clones. These structures may represent storage units for apical proteins and, therefore, the initiation sites for differentiation (1). This is in agreement with the presence of increased amounts of CEACAM1 and increased phosphorylation of p38 MAPK, the indicators of cell differentiation, in $\mathrm{H} 8$ cells. Immunocytochemical analysis showed CEACAM1 to be present predominantly in the intercellular vacuoles. It is in concert with the electronoptic finding of the brush border on the apical surface of these structures with tight microvilli in which the presence of CEACAM was demonstrated (20). The profound effect of sodium butyrate on the enzymatic activity of alkaline phosphatase in the $\mathrm{H} 8$ clone suggests that the level of alkaline phosphatase is a very sensitive marker of differentiation of the absorptive type of cells.

HT29 cells were found to be relatively resistant to butyrateinduced apoptosis (21). According to the levels of cleaved caspase- 3 and PARP detected in the clones, it appears that none of the four clones differed significantly in their apoptotic response to butyrate. However, electronoptic analyses demonstrated that less differentiated clones, G9 and A3, were more sensitive to butyrate-induced apoptosis; confirmed by observation of giant mitochondria, indicating the first steps of apoptosis (22), and clumped chromatin, indicating a late step of this process.

We intend to use the isolated clones in the further study of adenocarcinoma cell proliferation and differentiation. Surprisingly, data obtained from the analysis of HT29 cell clones again showed a great heterogeneity in the morphology and biochemical activities of these cloned cells. Huet et al (23) isolated both absorptive and mucus-secreting cells from the same clone of the HT29 cell line in the absence of glucose. Evidently, many HT29 cells contain the same information as the multipotential stem cells of normal intestinal crypts. Subcloning of the clones characterized in this study is currently in progress.

\section{Acknowledgements}

The technical assistance of Mrs. I. Lisková, I. Dosoudilová and J. Musilová is gratefully acknowledged. This study was supported by Reseach Project AVOZ50520514 of the Academy of Sciences of the Czech Republic and by Grant B5052302 of the Grant Agency of the Academy of Sciences of the Czech Republic.

\section{References}

1. Le Bivic A, Hirn M and Reggio H: HT-29 cells are an in vitro model for the generation of cell polarity in epithelia during embryonic differentiation. Proc Natl Acad Sci USA 85: 136-140, 1988.

2. Kruh J: Effects of sodium butyrate, a new pharmacological agent, on cells in culture. Mol Cell Biochem 42: 65-82, 1982.

3. Schroy PC, Rustgi AK, Ikonomu E, Liu XP, Polito J, Andry C, and O'Keane JC: Growth and intestinal differentiation are independently regulated in HT29 colon cancer cells. J Cell Physiol 161: 111-123, 1994.

4. Kucerová D, Stokrová J, Korb J, Sloncová E, Tuhácková Z and Sovová V: Response of HT29 cells to butyrate depends on time of exposure and glucose deprivation. Int J Mol Med 10: 779-784, 2002.

5. Pinto M, Appay MD, Simon-Assmann P, Chevalier G, Dracopoli N, Fogh J and Zweibaum A: Enterocytic differentiation of cultured human colon cancer cells by replacement of glucose by galactose in the medium. Biol Cell 44: 193-196, 1982 .

6. Soergel KH: Colonic fermentation: metabolic and clinical implications. Clin Investig 72: 742-748, 1994.

7. Emanuele S, D'Anneo A, Bellavia G, Vassallo B, Lauricella M, De Blasio A, Vento R and Tesoriere G: Sodium butyrate induces apoptosis in human hepatoma cells by a mitochondria/ caspase pathway, associated with degradation of beta-catenin, pRb and Bcl-XL. Eur J Cancer 40: 1441-1452, 2004.

8. Hafez MM, Infante D, Winawer S and Friedman E: Transforming growth factor beta 1 acts as an autocrine-negative growth regulator in colon enterocytic differentiation but not in goblet cell maturation. Cell Growth Differ 1: 617-626, 1990.

9. Zweibaum A, Pinto M, Chevalier G, Dussaulx E, Triadou N, Lacroix B, Haffen K, Brun JL and Rousset M: Enterocytic differentiation of a subpopulation of the human colon tumor cell line HT-29 selected for growth in sugar-free medium and its inhibition by glucose. J Cell Physiol 122: 21-29, 1985.

10. Laboisse CL, Maoret JJ, Triadou N and Augeron C: Restoration by polyethylene glycol of characteristics of intestinal differentiation in subpopulations of the human colonic adenocarcinoma cell line HT29. Cancer Res 48: 2498-2504, 1988.

11. Augeron C and Laboisse CL: Emergence of permanently differentiated cell clones in a human colonic cancer cell line in culture after treatment with sodium butyrate. Cancer Res 44: 3961-3969, 1984

12. Lesuffleur T, Barbat A, Dussaulx E and Zweibaum A: Growth adaptation to methotrexate of HT-29 human colon carcinoma cells is associated with their ability to differentiate into columnar absorptive and mucus-secreting cells. Cancer Res 50: 6334-6343, 1990.

13. Sovová V, Stokrová J, Sloncová E, Kucerová D, Tuhácková Z and Korb J: Alterations in mitochondria function and morphology in HT29 cells upon conditions inducing differentiation and apoptosis. Int J Oncol 23: 1755-1760, 2003.

14. Dráberová L, Stanners CP and Dráber P: A novel monoclonal antibody specific for biliary glycoprotein (CD66a). Folia Biol (Praha) 43: 243-244, 1997.

15. Richterová Z, Liebl D, Horák M, Palková Z, Stokrová J, Hozák P, Korb J, Forstová J: Caveolae are involved in the trafficking of mouse polyomavirus virions and artificial VP1 pseudocapsids toward cell nuclei. J Virol 75: 10880-10891, 2001.

16. Tanaka K, Hinoda Y, Takahashi H, Sakamoto H, Nakajima Y and Imai K: Decreased expression of biliary glycoprotein in hepatocellular carcinomas. Int J Cancer 74: 15-19, 1997.

17. Raingeaud J, Gupta S, Rogers JS, Dickens M, Han J, Ulevitch RJ and Davis RJ: Pro-inflammatory cytokines and environmental stress cause p38 mitogen-activated protein kinase activation by dual phosphorylation on tyrosine and threonine. J Biol Chem 270: 7420-7426, 1995.

18. Yosimichi G, Nakanishi T, Nishida T, Hattori T, TakanoYamamoto T and Takigawa M: CTGF-Hcs24 induces chondrocyte differentiation through a p38 mitogen-activated protein kinase (p38 MAPK), and proliferation through a p44/42 MAPK/ extracellular-signal regulated kinase (ERK). Eur J Biochem 268: 6058-6065,

19. Phillips TE, Huet C, Bilbo PR, Podolsky DK, Louvard D and Neutra MR: Human intestinal goblet cells in monolayer culture: characterization of a mucus-secreting subclone derived from the HT29 colon adenocarcinoma cell line. Gastroenterology 94: 1390-1403, 1988. 
20. Sundberg U, Beauchemin N and Obrink B: The cytoplasmic domain of CEACAM1-L controls its lateral localization and the organization of desmosomes in polarized epithelial cells. J Cell Sci 117: 1091-104, 2004.

21. Tan S, Seow TK, Liang RC, Koh S, Lee CP, Chung MC and Hooi SC: Proteome analysis of butyrate-treated human colon cancer cells (HT-29). Int J Cancer 98: 523-531, 2002.

22. Wakabayashi T: Megamitochondria formation - physiology and pathology. J Cell Mol Med 6: 497-538, 2002.

23. Huet C, Sahuquillo-Merino C, Coudrier E and Louvard D: Absorptive and mucus-secreting subclones isolated from a multipotent intestinal cell line (HT-29) provide new models for cell polarity and terminal differentiation. J Cell Biol 105: 345-357, 1987. 